\title{
Performance Testing Of Semi Circular Contraction Critical Flow Flumes for Field Channels
}

\author{
K.Krupavati ${ }^{1}$, T.V.Satyanarayana ${ }^{2}$ and H.V.Hema Kumar $^{3}$ \\ ${ }^{1}$ Assistant Professor, College of Agricultural Engineering, Madakasira, Andra Pradesh, India \\ ${ }^{2}$ Dean of Agricultural Engineering \& Technology, ANGRAU, Hyderabad, Andra Pradesh, India \\ ${ }^{3}$ Assistant Professor, College of Agricultural Engineering, Bapatla, Andra Pradesh, India
}

\begin{abstract}
A laboratory experiment entitled "Flow Characteristics of Semi Circular Contraction Critical Flow Flumes for Low Discharges under Different Submergence Conditions" was conducted in a hydraulic flume with motorized bed slope alteration facility at the Hydraulics laboratory, College of Agricultural Engineering, Bapatla, India to study the effect of percentage of contraction and submergence on flow characteristics like critical depth, location of critical depth, accuracy of measurement and total quantity of material used etc. The experiment consisted of three different contractions $(20 \%, 40 \%$ and $60 \%)$ tested with three different discharges $\left(10 l s^{-1}, 14 l s^{-1}\right.$ and $\left.18 l s^{-1}\right)$ and four submergence levels (60\%, 70\%, 80\% and 90\%). Dimensional analyses were performed and end depth, throat width and discharge relationships were arrived. The discharges arrived conventionally based on critical depth and through equations derived through dimensional analysis were compared and presented. The deviation of discharge under free flow conditions depicted from Eq. $a$ and Eq. $b$ are within the range of $\pm 5 \%$ of actual discharge for all flumes. A single measurement of end depth in semi circular contraction critical flow flumes can be used for discharge computation in open channels, if the submergence conditions are below $80 \%$ in general. Semi circular contraction critical flow flumes can be used for discharge measurement in open channels with best accuracy of $\pm 5 \%$ equations developed.
\end{abstract}

\section{Introduction}

The rapidly increasing use of all available water resources and the increasing costs of on-farm irrigation development require economical use of irrigation water. Inequity in the distribution of water through the irrigation network cause lower irrigation efficiencies. To improve water management, it is strongly recommended that the irrigation water be accurately measured and regulated at all important points in an irrigation system. Cutthroat flume is one of the critical flow measuring devices for open channel flows. The flume has become popular compared to others mainly because of its simple geometry and horizontal bed, which make construction simple and reduce the cost. It is extensively used in irrigation systems in India. A circular flume is a cylinder installed axially in a prismatic channel can be used to measure discharge. However the circular flume, as presented by Hager (1985, 1986 and 1988) and Samani et al. (1991), has the disadvantage of trapping floating material, which affects reliability and function of structure. Replogle and Clemmens (1981) developed a portable flume to measure flow rates in standard concrete slip form irrigation canals. The flume resembled a broad crested weir with only two finished surfaces of long and flat weir crest and rounded approach ramp. Replogle and Clemmens (1981) reported that that critical flow flumes with contracted throat sections that are about twice as long as the maximum flow depth through the flumes produced stable and reliable calibrations accurate to $\pm 3-5 \%$. Samani and Megallanez (2000) developed a simple venturi flume for flow measurement in open channels. The flume was contracted using two half cylinders of PVC pipe which created a contraction. Three different half cylinders are used with $40 \%, 64 \%$ and $60 \%$ contractions. It has been shown that the modified cut throat can predict the measured flow rate with less than 5\% error. A cost of comparison of the flume showed that it can be constructed with less than $60 \%$ cost of cutthroat flume due to lower material and labor requirements. Present research work is carried out to test the accuracy of measurement of water under different submerged conditions by preparing semi-circular contraction critical flow flumes.

2.1. Experimental Setup

\section{Materials \& Methods}

A commercial make of hydraulic flume with motorized bed slope alteration facility, installed already in Fluid Mechanics and Hydraulics laboratory of College of Agricultural Engineering, Bapatla is used in the experiments of this study. 


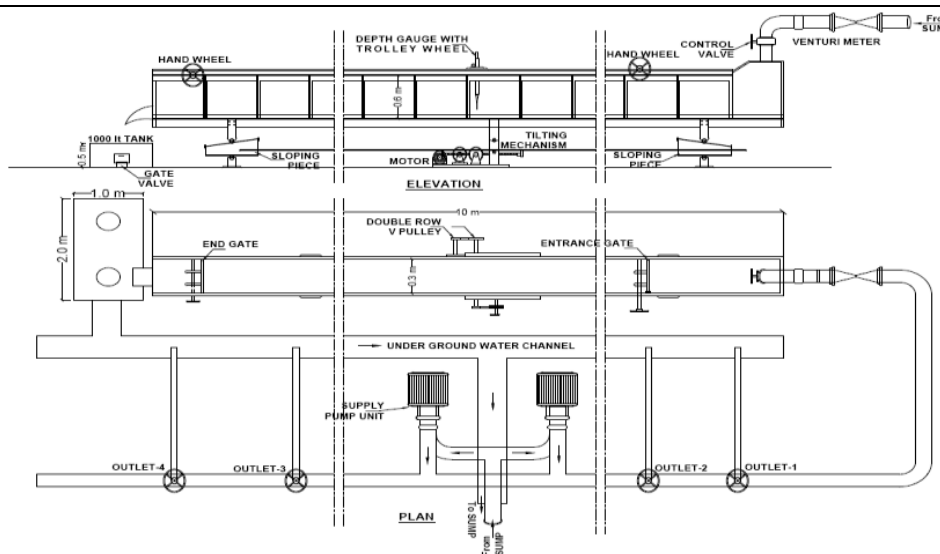

Figure 1. layout of experimental set up

Field channel in irrigation network carries a flow of 1 to $30 \mathrm{ls}^{-1}$. The normal flow available is between 10 to $30 \mathrm{ls}^{-1}$. Because of practical limitation of flow regulation in the laboratory and also the maximum flow available is $22 \mathrm{ls}^{-1}$, the experiment was planned to conduct at flows of $10 \mathrm{ls}^{-1}, \quad 14 \mathrm{ls}^{-1}$ and $18 \mathrm{ls}^{-1}$.

\subsection{Preparation of Semi Circular Contraction Critical Flow Flumes}

The development of models based on the design of simple flume for flow measurement in open channel was proposed by Samani and Magallanez (2000). The semi circular contraction flume was constructed by placing two semicircular cylinders (Fig 2) attached to the side walls of the rectangular channel portion of the hydraulic flume. In the present experiment, three flumes with three different contractions (Table 1) were prepared with seasoned teak wood with fine finish and were painted to have uniform roughness over the entire section and also to prevent from any damage due to submergence in water.

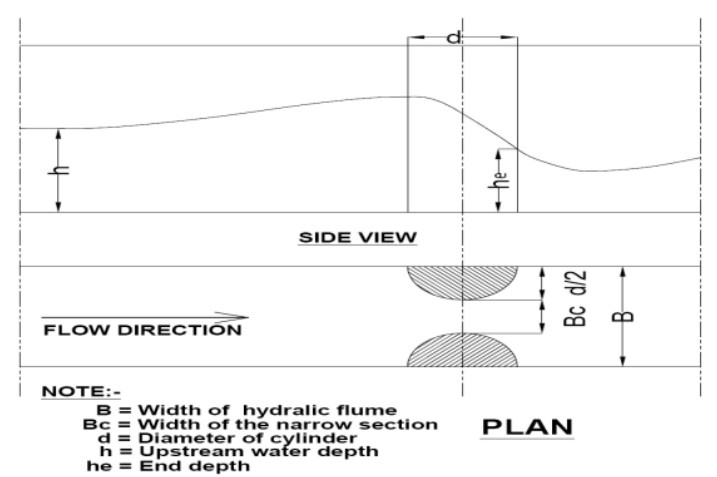

Figure 2. Semi circular contractions in the hydraulic flume

Table 1 Dimensions of critical flow flumes selected for experimentation.

\begin{tabular}{|c|c|c|c|}
\hline $\begin{array}{c}\text { Base } \\
\text { Width, } \\
\text { B (cm) }\end{array}$ & $\begin{array}{c}\text { Wooden } \\
\text { model } \\
\text { diameter, } \\
\text { d }(\mathbf{c m})\end{array}$ & $\begin{array}{c}\text { Throat } \\
\text { width, } \\
\mathbf{B}_{\mathbf{c}}(\mathbf{c m})\end{array}$ & $\begin{array}{c}\text { Contraction } \\
(\mathbf{\%}) \\
\left(\mathbf{d} / \mathbf{B}^{*} \mathbf{1 0 0}\right)\end{array}$ \\
\hline 30 & 6 & 24 & 20 \\
30 & 12 & 18 & 40 \\
30 & 18 & 12 & 60 \\
\hline
\end{tabular}

\subsection{Design of Experiments}

A scheme of experiments has been planned and performed by fixing a set of semi circular contractions to form one critical flow flume at a distance of $2 \mathrm{~m}$ from the end of tail gate. The scheme of experiments consists of different series with various levels of the selected variables combined into factorial set of treatments. The following are the levels of experimental variables.

I. Flume types : 3

a. Flume-1 with diameter of $6 \mathrm{~cm}$ and throat width of $24 \mathrm{~cm}$

b. Flume-2 with diameter of $12 \mathrm{~cm}$ and throat width of $18 \mathrm{~cm}$

c. Flume-3 with diameter of $18 \mathrm{~cm}$ and throat width of $12 \mathrm{~cm}$ 


II. Discharges: $3 \quad 10 \mathrm{ls}^{-1}, 14 \mathrm{ls}^{-1}$ and $18 \mathrm{ls}^{-1}$.

III. Submergence conditions: $4 \quad 60 \%, 70 \%, 80 \%$ and $90 \%$.

\subsection{Experimental procedure}

Starting with the free flow condition, the submergence condition has been increased gradually to $60 \%$ submergence, $70 \%$ submergence, $80 \%$ submergence and $90 \%$ submergence with the help of tail gate provided at the end of the flume. The process of recording the water surface profiles has been repeated with remaining two discharges of $14 \mathrm{ss}^{-1}$ and $18 \mathrm{ls}^{-1}$ and four different submergence conditions for each flume type. The semi circular contracted flume- 1 has been replaced by flume- 2 and flume- 3 subsequently taking all precautions as in the installation of flume-1.

\subsection{Computation of Critical Depth}

A theoretical criterion for critical flow by definition is the state of flow the specific energy is minimum for a given discharge.

From continuity equation

$\mathrm{Q}=\mathrm{AV}=\mathrm{A}_{\mathrm{c}} \mathrm{V}_{\mathrm{c}}$

$\mathrm{V}_{\mathrm{c}}=\mathrm{Q} / \mathrm{A}_{\mathrm{c}}$

From Bernoulli's equation

$\mathrm{H}_{1}=\mathrm{H}=\mathrm{y}+\mathrm{v}^{2} / 2 \mathrm{~g}$,

Where

$\mathrm{Q}=$ volume rate of flow, $1 \mathrm{~s}^{-1}$

$\mathrm{V}=$ Average velocity, $\mathrm{m} / \mathrm{s}$

$\mathrm{A}=$ cross-sectional area of flow, $\mathrm{m}^{2}$

$\mathrm{H}=$ total energy head, $\mathrm{m}$

$\mathrm{g}=$ Acceleration due to gravity, $\mathrm{m} / \mathrm{s}^{2}$

$\mathrm{y}=$ Water depth, $\mathrm{m}$

Substitution of (1) in (2) gives

$$
\begin{aligned}
& H_{1}=H=y+\frac{Q^{2}}{2 g A^{2}} \quad \text { or } \\
& \frac{d H}{d y}=\left(1-\frac{Q^{2}}{g A^{3}}\right) \frac{d A}{d y}=\left(1-\frac{V^{2}}{g A}\right) \frac{d A}{d y}
\end{aligned}
$$

The water area dA near the surface is equal to Bdy, then the equation becomes

$$
\frac{d H}{d y}=1-\frac{V^{2} B}{g A}
$$

At the critical state of flow, the above equation therefore gives

$$
\frac{V_{c}^{2}}{2 g}=\frac{A_{c}}{2 B_{c}}
$$

Where $A c=B_{c} Y_{c}$

Substituting (1) in (3)

$$
Y_{c}^{3}=\frac{Q^{2}}{g B_{c}^{2}}
$$

Where, the subscript 'c' relates to critical condition. Froude number $\left(\frac{V_{c}}{\sqrt{g y_{c}}}\right), \mathrm{Fr}=1$ at critical conditions. Critical depths for three discharges and three contractions have been computed from equation (4). The critical depths have been located on plotted water surface profiles to investigate flume contractions and submergence conditions.

\subsection{Dimensional Analysis}

Dimensional analysis is a mathematical technique which makes use of the study of dimensions as an aid to the solution of several engineering problems. It helps in determining a systematic arrangement of variables in 
the physical relationship and combining the dimensions. The dimensional analysis methods followed in this study have been presented in the following sections.

\subsubsection{Method of repeating variables}

In the present study the method of repeating variables is used in deriving an expression for predicting the discharge.

General expression for the discharge is written as

$$
\mathrm{Q}=\left(\mathrm{h}, \mathrm{h}_{\mathrm{e}}, \mathrm{Y}_{\mathrm{c}}, \mathrm{B}, \mathrm{B}_{\mathrm{c}}, \mathrm{g}, \mu\right)
$$

Where $\mathrm{Q}=$ actual discharge, $\mathrm{B}=$ channel width

$\mathrm{B}_{\mathrm{c}}=$ Throat width, $\mathrm{h}=$ upstream water depth

$\mathrm{h}_{\mathrm{e}}=$ water depth at flume end, $\mathrm{Y}_{\mathrm{c}}=$ critical depth.

$\mathrm{g}=$ Acceleration due to the gravity

$\mu=$ Absolute viscosity of water.

Out of the total variables included in the study, one geometric, one kinematic and one dynamic variable is chosen. In the present study throat width $\left(\mathrm{B}_{\mathrm{c}}\right)$, acceleration due to gravity $(\mathrm{g})$, and viscosity of water $(\mu)$ are selected as the repeating geometric variable, kinetic variable and dynamic variables respectively.

By making each term dimensionless through a combination of selected variables and by eliminating the primary quantities of mass $(\mathrm{M})$, time $(\mathrm{T})$, and length $(\mathrm{L})$ in sequence, the final expression is found to be

$$
\frac{Q}{g^{1 / 2} B_{c}^{5 / 2}}=f\left(\frac{h}{B_{c}}, \frac{h_{e}}{B_{c}}, \frac{B}{B_{c}}, \frac{Y_{c}}{B_{c}}\right)
$$

However, this equation is also cross checked with the equation derived from Buckingham Pi theorem and both of them are in conformity with each other as explained in the following section.

\subsubsection{Buckingham Pi theorem}

The relationship between the end water depth, $h_{e}$, and discharge, $Q$, for a flume constructed by contracting the width from $B$ to $B_{c}$ is carried out by Buckingham Pi theorem. The variables involved in the experiment are discharge $(\mathrm{Q})$, upstream water depth $(\mathrm{h})$, width of the channel $(\mathrm{B})$, throat width $\left(\mathrm{B}_{\mathrm{c}}\right)$, Viscosity of water $(\mu)$, and end section depth $\left(h_{\mathrm{e}}\right)$. Number of independent variables are 7 , and number of fundamental units are 3. Therefore, number of dimensionless numbers are 4 (7-3). The functional relationship between three dimensionless numbers is

$$
\mathrm{F}\left(\pi_{1}, \pi_{2}, \pi_{3}, \pi_{4}\right)=0
$$

Where, $\pi_{1}, \pi_{2}, \pi_{3}$, and $\pi_{4}$ are dimensionless numbers, whose expression has to be determined. Choosing $\mathrm{B}_{c}, \mathrm{~g}$ and $\mu$ as repeating independent variables,

$$
\pi_{1}=\mathrm{B}_{\mathrm{c}}{ }^{\mathrm{a}} \mathrm{g}^{\mathrm{b}} \mu^{\mathrm{c}} \mathrm{Q}
$$

Where $a, b$ and $c$ are numerical constants. Substitute fundamental units of each variable in eq. (2).

$$
0=\mathrm{L}^{\mathrm{a}} \mathrm{L}^{\mathrm{b}} \mathrm{T}^{-2 \mathrm{~b}} \mathrm{M}^{\mathrm{c}} \mathrm{L}^{-2 \mathrm{c}} \mathrm{L}^{3} \mathrm{~T}^{-1}
$$

By solving above equation, $a=-5 / 2, \quad b=-1 / 2$ and $c=0$.

Substituting $\mathrm{a}, \mathrm{b}$ and $\mathrm{c}$ values in equation (2)

$$
\pi_{1}=\frac{Q}{B_{c}^{5 / 2} g_{c}^{1 / 2}}=\left(\frac{Y_{c}}{B_{c}}\right)^{3 / 2}
$$

Where $Y_{c}$ is critical depth in the narrow section having width $B_{c}$

Similarly,

$$
\begin{aligned}
& \pi_{2}=\frac{h}{B_{c}} \\
& \pi_{3}=\frac{B}{B_{c}} \\
& \pi_{4}=\frac{h_{e}}{B_{c}}
\end{aligned}
$$

Substituting equation (3), (4), (5) and (6) in (2)

$$
f\left(\frac{Y_{c}}{B_{c}}, \frac{h}{B_{c}}, \frac{h_{e}}{B_{c}}, \frac{B}{B_{c}}\right)=0
$$




$$
\begin{aligned}
& \frac{Y_{c}}{B_{c}}=\phi\left(\frac{h_{e}}{B_{c}}\right) \\
& \frac{Y_{c}}{B_{c}}=c\left(\frac{h_{e}}{B_{c}}\right)^{n} \\
& \left(\frac{Q}{g^{1 / 2} B_{c}^{5 / 2}}\right)^{2 / 3}=c\left(\frac{h_{e}}{B_{c}}\right)^{n}
\end{aligned}
$$

Where $\mathrm{a}, \mathrm{b}$ are numerical constants.

$$
\frac{Q}{g^{1 / 2} B_{c}^{5 / 2}}=f\left(\frac{h_{e}}{B_{c}}\right)
$$

\section{Results And Discussion}

To evaluate the performance of semi circular contraction critical flow flumes and to estimate the accuracy through the deviations in discharges under free flow and submerged conditions, the discharges from the flumes of all contractions computed from Eq. (a) and (b) have been compared with actual discharges (Table. 2). The deviation of discharge under free flow conditions depicted in Fig. 3 and Fig. 4 are within the range of \pm $10 \%$ of actual discharge.

The equations arrived on least square method are

$$
\begin{aligned}
& \left(\frac{Q}{\sqrt{g} B_{c}^{5 / 2}}\right)^{2 / 3}=0.00635\left(\frac{h_{e}}{B_{c}}\right)^{0.7435} \ldots \text { For flume-1 } \\
& \left(\frac{Q}{\sqrt{g} B_{c}^{5 / 2}}\right)^{2 / 3}=0.00908\left(\frac{h_{e}}{B_{c}}\right)^{0.7798} \ldots \text { For flume-2 } \\
& \left(\frac{Q}{\sqrt{g} B_{c}^{5 / 2}}\right)^{2 / 3}=0.0164\left(\frac{h_{e}}{B_{c}}\right)^{1.0913} \ldots \text { For flume-3 }
\end{aligned}
$$

Where $\mathrm{Q}=$ actual discharge, $\mathrm{B}=$ channel width

$\mathrm{B}_{\mathrm{c}}=$ Throat width, $\mathrm{h}=$ upstream water depth

$\mathrm{h}_{\mathrm{e}}=$ water depth at flume end,

$\mathrm{g}=$ Acceleration due to the gravity.

Relationship between discharge and end depth has been derived for all contractions

$$
\begin{aligned}
& Q=1.2921 h_{e}^{1.1152} \\
& Q=1.05702 h_{e}^{1.2618} \\
& Q=0.570 h_{e}^{1.632}
\end{aligned}
$$

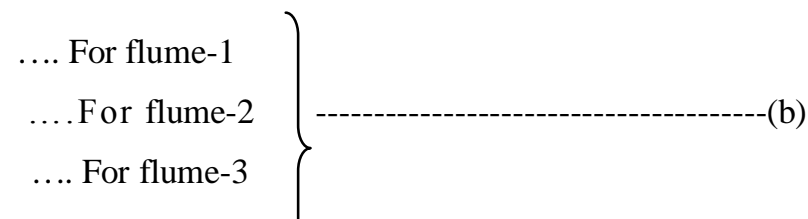

\subsection{Comparison under free flow condtions}

In case of Eq. (a) for $20 \%$ contraction flume the average deviations in discharge (Fig. 3) are $-6.93 \%$, $8.91 \%$ and $-1.45 \%$ at $18 \mathrm{ls}^{-1}, 14 \mathrm{ss}^{-1}$ and $10 \mathrm{ss}^{-1}$ under free flow condition respectively. The same are arrived as (Fig. 4) $-6.9 \%, 8.9 \%$ and $-1.45 \%$ respectively using Eq. (b) which show that both equations are in agreement with each other for the flume with $20 \%$ contraction. In case of flume-2 with $40 \%$ contraction, the average deviation in discharge is slightly more with Eq. (a). The percent of errors are $-2.0 \%,-1.944 \%$ and $+2.38 \%$ for Eq. (a) and $+0.614 \%,-1.29 \%$ and $+0.713 \%$ for the discharges of $18 \mathrm{ls}^{-1}, 14 \mathrm{ls}^{-1}$ and $101 \mathrm{~s}^{-1}$ for equation (b). The similar agreement of results is also observed with $60 \%$ contraction flumes as $-1.612 \%,+1.17 \%$ and $-1.116 \%$ for Eq. (a) and $-1.191 \%$ and +1.68 and $-0.517 \%$ for the discharges of $18 \mathrm{ss}^{-1}, 14 \mathrm{ls}^{-1}$ and $10 \mathrm{ls}^{-1}$ respectively.

It has been concluded from above results that semi circular contraction critical flow flumes are used for discharge measurement in open channels with best accuracy with end depth-discharge relationships developed for different contractions with single measurement of end depth of flume with known contraction in case of Eq. (a). As the critical flow conditions do not occur in the throat section with flume- 1 with $20 \%$ contraction, even 
though the average deviations in discharges measured are within the range of $\pm 10 \%$ but it is not suitable to measure discharge.

\subsection{Comparison under submergence conditions.}

The discharges from the flumes of all contractions under submerged conditions computed from Eq. (a) and (b) have been compared with actual discharges (Table 2). The flume- 2 with $40 \%$ contraction is tolerant up to $80 \%$ submergence condition and the flume- 3 with $60 \%$ contraction is tolerant up to $70 \%$ submergence condition to measure discharge with little variations in the flow characteristics. If the submergence conditions are increased from $70 \%$ to $80 \%$ with flume- 3 of $60 \%$ contraction, the percent error in discharge has increased up to $21 \%$. With the highest submergence of $90 \%$, the deviations in discharges are much larger.

For flume- 2 with $40 \%$ contraction at $80 \%$ submergence, average deviations in discharges increased from $3.30 \%$ to $15.87 \%$ and $6.5 \%$ to $15.09 \%$ with decrease in discharge from $18 \mathrm{ls}^{-1}$ to $10 \mathrm{ls}^{-1}$ in case of Eq. (a) and Eq. (b) respectively. For flume-3 with $60 \%$ contraction at $70 \%$ submergence, average deviations in discharges varied as $7.68 \%, 10.98 \%$ and $8.4 \%$ in case of Eq. (a) and $8.177 \%, 11.48 \%$ and $9.02 \%$ with the discharges of $18 \mathrm{ss}^{-1}, 14 \mathrm{ls}^{-1}$ and $10 \mathrm{ls}^{-1}$ in case of Eq. (b) respectively. For flume-3 with $60 \%$ contraction at $80 \%$ submergence, maximum deviations in discharges $21.27 \%$ and $21.93 \%$ have been observed in case of Eq. (a) and Eq. (b) respectively.

At $90 \%$ submergence condition, the percent error ranged from $35.1 \%$ to $91.17 \%$ and $28.79 \%$ to $70.59 \%$ in case of Eq. (a) and Eq. (b). Based on the analysis of results, it is concluded that a single measurement of end depth in semi circular contraction critical flow flumes can be used for discharge computation in open channels, if the submergence conditions are below $80 \%$ in general. However, the percent of deviations in discharges will be different for different contractions.

Table 2. Predicted discharges and percent of error of Eq. (a) and (b) of semi circular contraction flumes for different discharges and contractions

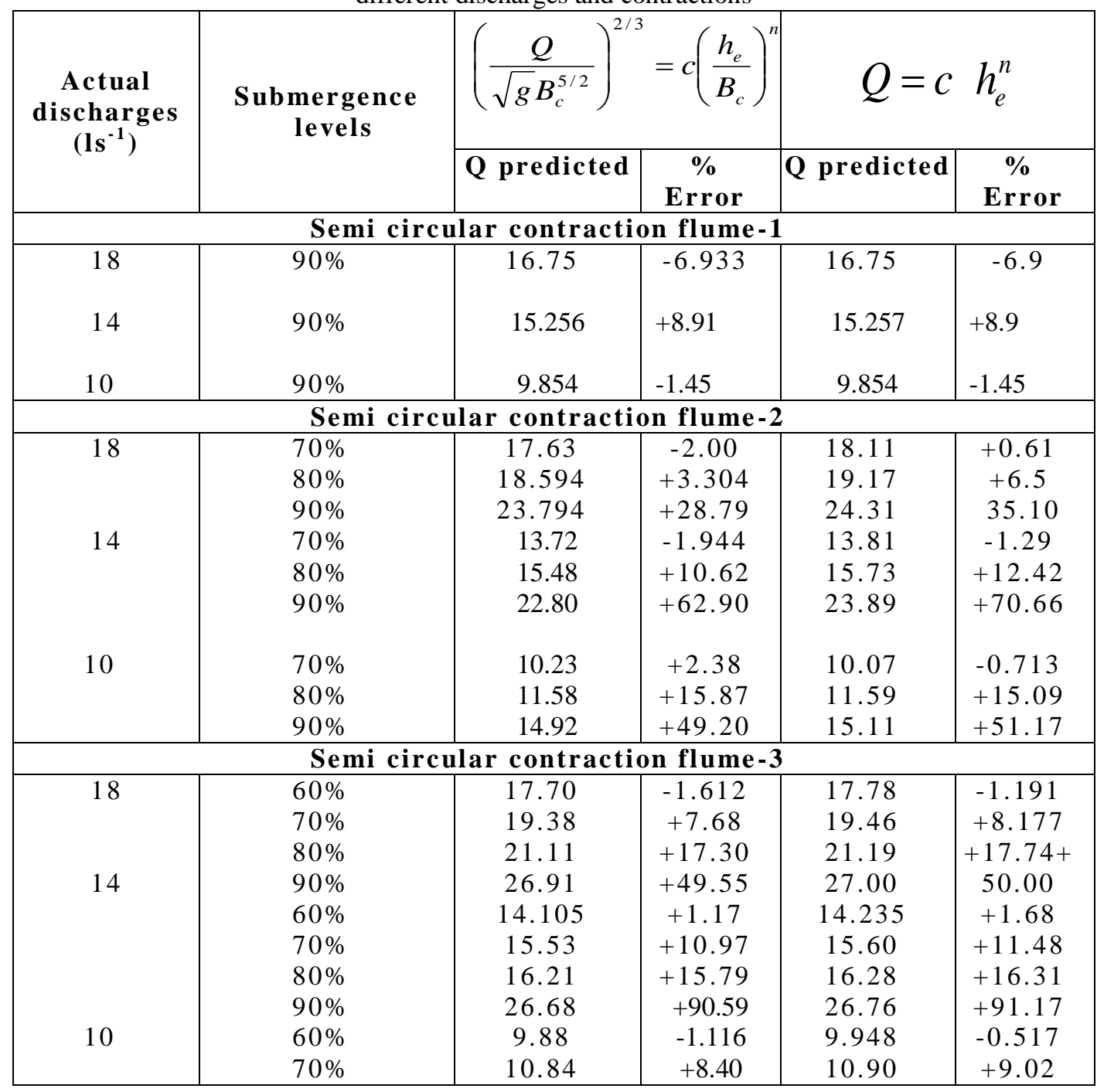




\begin{tabular}{|l|c|c|c|c|c|}
\hline & $80 \%$ & 12.12 & +21.27 & 12.19 & +21.93 \\
& $90 \%$ & 15.64 & +56.46 & 15.71 & +57.19 \\
\hline
\end{tabular}

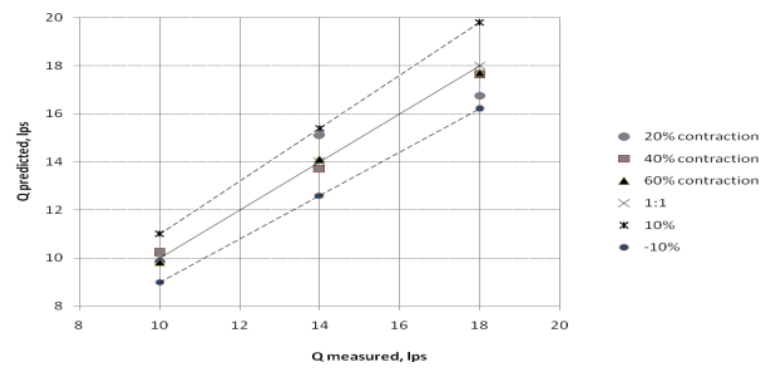

Figure 3 Comparison between measured discharge and predicted discharge calculated by Eq. (a) under free flow conditions.

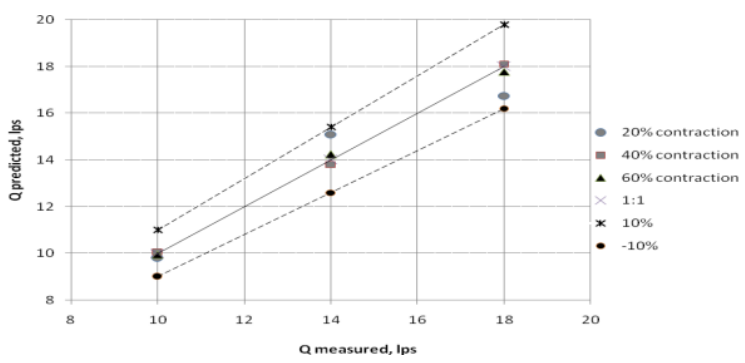

Figure 4 Comparison between measured discharge and predicted discharge calculated by Eq. b under free flow conditions.

IV.

CONCLUSIONS

Critical flow conditions do not occur in the throat section with flume-1 with $20 \%$ contraction and hence it is not suitable to measure discharge. It is concluded that $20 \%$ contraction is not sufficient to create critical flow conditions. The location of critical depth moved towards the end of the flume at all discharges in case of flume- 2 and flume- 3 with increase in submergence levels up to $80 \%$ submergence. The location of critical depth moved towards the center of the flume at all discharges with increase in contraction from $40 \%$ to $60 \%$. Critical depth occurs at only one location in the throat section for all possible conditions tested. With the highest submergence condition of $90 \%$ level, the location of critical depth is not found in the throat section at all discharges for all flumes indicating that the side contracted flumes are sensitive to higher submergence conditions. A single measurement of end depth in semi circular contraction critical flow flumes can be used for discharge computation in open channels, if the submergence conditions are below $80 \%$ in general. Semi circular contraction critical flow flumes can be used for discharge measurement in open channels with best accuracy of \pm $5 \%$ using the equations developed. Semi circular contraction critical flow flumes can be used for discharge measurement in open channels with best accuracy of $\pm 5 \%$ equations developed.

\section{References}

[1] W. H. Hager, Modified venturi channel. Journal of Irrigation and Drainage Engineering, ASCE, 111(1), 1985, 19-35.

[2] W. H. Hager, Modified trapezoidal venturi channel. Journal of Irrigation and Drainage Engineering, ASCE, 112(3), 1986, $225-241$.

[3] W. H. Hager, Mobile flume for circular channel. Journal of Irrigation and Drainage Engineering, ASCE, 114(3), 1988, 520-534.

[4] Z. Samani, S. Jorat, and M. Yousaf. Hydraulic characteristics of circular flume. Journal of Irrigation and Drainage, ASCE, 117(4), 1991, 558-566.

[5] Replogle, J. A. and A. J. Clemmens. Measuring flumes of simplified constructions. Transactions of ASAE, 24(2), 1981, 366-374

[6] Samani, Z., and H. Magallnez, Simple flume for flow measurement in open channel. Journal of Irrigation and Drainage, ASCE, $126(2), 2000,127-129$ 